\title{
Vitamin D in adult health and disease: a review and guideline statement from Osteoporosis Canada
}

\author{
David A. Hanley MD, Ann Cranney MB BCh, Glenville Jones PhD, Susan J. Whiting PhD, \\ William D. Leslie MD, David E.C. Cole MD PhD, Stephanie A. Atkinson PhD, \\ Robert G. Josse MB ChB, Sidney Feldman MD, Gregory A. Kline MD, Cheryl Rosen MD; \\ for the Guidelines Committee of the Scientific Advisory Council of Osteoporosis Canada
}

Previously published at www.cmaj.ca

$\infty$ See also the summary article by Hanley and colleagues

$\mathrm{T}$ he 2002 guidelines for the management of osteoporosis published by Osteoporosis Canada ${ }^{1}$ identified adequate vitamin D status, in addition to calcium from diet or supplements, as essential for the prevention of osteoporosis. Recent large clinical trials and meta-analyses have expanded our knowledge of the role of vitamin D in fractures, falls and other health outcomes, as well as its effect on disorders such as diabetes mellitus, autoimmune and infectious diseases, malignancies and cardiovascular disease.

Current Canadian recommendations for "adequate intake" and "tolerable upper level" of vitamin D, which are more than 10 years old, were derived mainly from early nutritional science estimates of the minimal intake necessary to prevent florid deficiency states (rickets or osteomalacia). However, these levels have never been supported by adequately conducted dose-finding studies. ${ }^{2}$

This review is an update to the 2002 recommendations on vitamin D and is specific for adults, excluding times of pregnancy and lactation.

\section{Methods}

We systematically searched the MEDLINE database, for the period 1996 to June 30, 2008, and the Cochrane Library using the terms "vitamin D," "vitamin D deficiency," "25-hydroxyvitamin D," "meta-analysis" and "systematic review." We identified 168 potentially relevant papers. Of these, 16 relevant systematic reviews remained after removal of duplicates and screening of abstracts by two reviewers (including A.C.). We included systematic reviews of randomized controlled trials and observational studies that assessed fractures, falls, death or extraskeletal outcomes. We used the Assessment of Multiple Systematic Reviews instrument ${ }^{3}$ to evaluate the methodologic quality of systematic reviews published between the cutoff date for literature reviewed in the 2002 clinical practice guidelines ${ }^{1}$ until June 30, 2008 (Appendices 1 and 2, available at www.cmaj.ca/cgi/content/full/cmaj .080663/DC1). A multidisciplinary expert panel consisting of the authors of this paper reviewed the abstracted articles and

\section{Key points}

- Adequate vitamin $D$ is an essential factor in the prevention of osteoporosis and may reduce the risk of other medical disorders unrelated to bone and mineral metabolism.

- To most consistently improve clinical outcomes such as fracture risk, an optimal serum level of 25-hydroxyvitamin $\mathrm{D}$ is probably above $75 \mathrm{nmol} / \mathrm{L}$; for most Canadians, supplementation is needed to achieve this level.

- The recommended vitamin D intake is $10-25 \mu \mathrm{g}$ (400-1000 IU) daily for low-risk adults under 50 years of age and $20-50 \mu \mathrm{g}$ (800-2000 IU) for high-risk and older adults, with potential for consideration of higher doses.

- Doses up to $50 \mu \mathrm{g}$ (2000 IU) are safe and do not require monitoring, but if higher doses are sometimes needed, monitoring is appropriate.

quality measures. Following this review, we formulated summary statements based upon the highest level of evidence and developed graded recommendations. All authors contributed to this process, reaching consensus through a series of in-person meetings, teleconferences and electronic communications. Levels of evidence and grading of recommendations followed the same system as used in 2002 (Table 1). ${ }^{1}$ The Guidelines Committee and the Executive Committee of Osteoporosis Canada's Scientific Advisory Council approved the recommendations.

From the Departments of Medicine (Hanley, Kline), Oncology (Hanley) and Community Health Sciences (Hanley), University of Calgary, Calgary, Alta. the Department of Medicine (Cranney), University of Ottawa, Ottawa, Ont.; the Department of Biochemistry (Jones), Queen's University, Kingston, Ont.; the College of Pharmacy and Nutrition (Whiting), University of Saskatchewan, Saskatoon, Sask.; the Departments of Radiology, Nuclear Medicine and Medicine (Leslie), University of Manitoba, Winnipeg, Man.; the Departments of Pathology (Cole), Laboratory Medicine (Cole), Medicine (Josse, Rosen), and Family and Community Medicine (Feldman), University of Toronto, Toronto, Ont.; and the Department of Pediatrics (Atkinson), McMaster University, Hamilton, Ont. Members of the Guidelines Committee of the Scientific Advisory Council of Osteoporosis Canada are listed in the Acknowledgements section of this article.

CMAJ 2010. DOI:10.1503/cmaj.080663 


\section{Assessment of vitamin D}

\section{Measurement and assay}

After synthesis in the skin or dietary ingestion, vitamin D is removed from the bloodstream into various tissues, including the liver, adipose tissue and muscle. Its biologic half-life is about 60 days, ${ }^{4}$ and it is eventually converted to 25 -hydroxyvitamin $\mathrm{D}$ in the hepatocytes. ${ }^{4.5}$ Vitamin $\mathrm{D}_{3}$ (cholecalciferol) is the molecule synthesized in the skin in response to ultraviolet $B$ radiation, whereas vitamin $D_{2}$ (ergocalciferol) is derived from irradiation of certain fungi. Both vitamin $\mathrm{D}_{2}$ and vitamin $\mathrm{D}_{3}$ create 1,25 -dihydroxyvitamin $\mathrm{D}$, the active form, although there is some evidence that vitamin $\mathrm{D}_{2}$ may not be used in the body as efficiently as vitamin $\mathrm{D}_{3}{ }^{6}$ In Canada, most vitamin $\mathrm{D}$ supplements consist of vitamin $\mathrm{D}_{3}$, but high-dose preparations, available by prescription, are vitamin $\mathrm{D}_{2}$. In this paper we use the term "vitamin D" to refer to both forms, unless a distinction is warranted.

The serum concentration of 25-hydroxyvitamin $\mathrm{D}_{3}$ is the best indicator of the nutritional and functional status of vitamin D. ${ }^{2}$ A nonfasting sample taken at any time of day is suitable for measurement of 25-hydroxyvitamin D (level 2 evidence). Circulating calcitriol (1 $\alpha, 25$-dihydroxyvitamin $\mathrm{D}_{3}$ or 1,25-dihydroxycholecalciferol) is the vitamin $\mathrm{D}$ hormone regulating intestinal calcium and phosphate absorption, but it is not an appropriate indicator of clinical vitamin D status,"

Table 1: Levels of evidence and grading system*

\begin{tabular}{|c|c|}
\hline Level or grade & Criteria \\
\hline \multicolumn{2}{|l|}{ Evidence } \\
\hline $1+$ & $\begin{array}{l}\text { Systematic overview or meta-analysis of } \\
\text { randomized controlled trials }\end{array}$ \\
\hline 1 & $\begin{array}{l}\text { Randomized controlled trial with } \\
\text { adequate power }\end{array}$ \\
\hline $2+$ & $\begin{array}{l}\text { Randomized controlled trial that does } \\
\text { not meet level } 1 \text { criteria }\end{array}$ \\
\hline 3 & $\begin{array}{l}\text { Nonrandomized clinical trial or cohort } \\
\text { study }\end{array}$ \\
\hline 4 & $\begin{array}{l}\text { Before-after study, cohort study with } \\
\text { noncontemporaneous controls, case- } \\
\text { control study }\end{array}$ \\
\hline 5 & Case series with controls \\
\hline 6 & Case series without controls \\
\hline \multicolumn{2}{|c|}{ Recommendation } \\
\hline A & $\begin{array}{l}\text { Supported by level } 1 \text { or } 1+\text { evidence } \\
\text { plus consensus }\end{array}$ \\
\hline B & $\begin{array}{l}\text { Supported by level } 2 \text { or } 2+\text { evidence } \\
\text { plus consensus }\end{array}$ \\
\hline C & $\begin{array}{l}\text { Supported by level } 3 \text { evidence plus } \\
\text { consensus }\end{array}$ \\
\hline $\mathrm{D}$ & $\begin{array}{l}\text { Any lower level of evidence supported } \\
\text { by consensus }\end{array}$ \\
\hline
\end{tabular}

*Identified articles were reviewed, and the summary statements developed from these articles were assigned a level of evidence (from $1=$ highest to $4=$ lowest). Recommendations were assigned a grade, according to a system that incorporated both level of evidence and expert consensus (from A = highest to $D=$ lowest). the exception being in patients with abnormalities of calcitriol synthesis (e.g., sarcoidosis) or rare disorders of phosphate or vitamin D metabolism (level 4 evidence, grade D recommendation).

Many techniques are widely available for measuring 25hydroxyvitamin D. ${ }^{7-9}$ These assays all perform reasonably well in identifying clinically important low levels (Table 2), but methods other than high-performance liquid chromatography may misclassify about $20 \%$ of low values. ${ }^{7-9}$ However, the data used to define current clinical decision values for 25hydroxyvitamin D concentrations were obtained by means of immunoassays. Variability in measurements of serum 25hydroxyvitamin D make it imperative that clinical laboratories participate in external laboratory proficiency testing programs, ${ }^{7-9}$ such as the Vitamin D External Quality Assessment Scheme. ${ }^{10}$ External proficiency testing should be a mandatory component of accreditation for laboratories that measure 25-hydroxyvitamin D (level 2 evidence).

\section{Monitoring of serum 25-hydroxyvitamin D}

There has been a marked increase in the clinical use of 25hydroxyvitamin D assays. ${ }^{11}$ However, serum 25-hydroxyvitamin D should be measured only if deficiency is suspected or would affect the person's response to therapy (e.g., in cases of impaired intestinal absorption, such as celiac disease, or osteoporosis requiring pharmacologic therapy). In treating deficiency, serum 25-hydroxyvitamin $\mathrm{D}$ will indicate the effectiveness of vitamin D therapy. The half-life of 25hydroxyvitamin $\mathrm{D}$ in the body is $15-20$ days. ${ }^{4}$ With standarddose supplementation, serum 25-hydroxyvitamin D plateaus after three to four months. ${ }^{12}$ Therefore, serum 25-hydroxyvitamin D should be checked no sooner than three months after standard-dose treatment is initiated (level 2 evidence, grade $\mathrm{B}$ recommendation). After high-dose oral or parenteral vitamin D replacement is administered (e.g., $500000 \mathrm{IU}$ ), the peak 25-hydroxyvitamin $\mathrm{D}$ level may be achieved in one month..$^{13}$ Patients taking daily doses above Health Canada's "tolerable upper intake level" (currently set at $50 \mu \mathrm{g}$ [2000 IU]) should undergo monitoring of serum 25-hydroxyvitamin D (level 4 evidence, grade D recommendation). For healthy Canadians, the dose recommendations for routine supplementation in this paper should result in adequate blood levels. Monitoring of routine supplement use and routine testing of

Table 2: Classification of vitamin $D$ status by serum level of 25-hydroxyvitamin D (25-OH-D)

\begin{tabular}{llc}
\hline $\begin{array}{l}\text { Serum } 25-\mathrm{OH}-\mathrm{D}, \\
\mathrm{nmol} / \mathrm{L}^{*}\end{array}$ & \multicolumn{1}{c}{ Category } & $\begin{array}{c}\text { Level of } \\
\text { evidence }\end{array}$ \\
\hline$<25$ & Vitamin D deficiency & 3 \\
$25-75$ & Vitamin D insufficiency $\neq$ & 2 \\
$>75$ & Desirable vitamin D status & 3 \\
$>250$ & Potential adverse effects & 2 \\
\hline
\end{tabular}

*Assumes that serum $25-\mathrm{OH}-\mathrm{D}$ is measured by a clinical laboratory participating in an external quality assurance program.

$+2.5 \mathrm{nmol} / \mathrm{L}=1 \mathrm{ng} / \mathrm{mL}$.

$\neq$ "Insufficiency" is a milder form of deficiency and should preferably be termed "suboptimal vitamin D status." 
otherwise healthy individuals as a screening procedure are not indicated (grade D recommendation).

\section{Vitamin D status}

Vitamin D deficiency should be regarded as a continuum, encompassing past definitions of "deficiency" and "insufficiency" (Table 2). The term "deficiency" was previously used to describe the advanced clinical effects of chronically low vitamin D: malabsorption of calcium and phosphate with resultant hypocalcemia, hypophosphatemia and secondary hyperparathyroidism, as well as proximal myopathy and impaired growth-plate development (rickets) and bone mineralization (osteomalacia) ${ }^{5}$ (level 3 evidence). Vitamin D "insufficiency" described a milder form of deficiency in which reduced absorption of calcium and resultant mild secondary hyperparathyroidism might increase bone loss. Vitamin D insufficiency commonly occurs in patients with osteoporosis and could contribute to their clinical presentation of low bone density, fractures and falls ${ }^{5}$ (level 2 evidence; see "Traditional roles," later in this article).

In rickets and osteomalacia, serum levels of 25-hydroxyvitamin D are usually below 20-25 nmol/L, whereas levels of vitamin D in "insufficiency" are below the desirable range but above 20-25 nmol/L. The lower limit of the desirable (optimal) range is debatable, but available evidence supports setting this at $75-80 \mathrm{nmol} / \mathrm{L}^{12-17}$ (level 3 evidence). Setting an optimal level of $75 \mathrm{nmol} / \mathrm{L}$ makes certain the person has reached the point at which, with increasing vitamin $\mathrm{D}$ intake, serum parathyroid hormone, intestinal calcium absorption ${ }^{15}$ and muscle function in the lower extremities ${ }^{14}$ have reached a plateau and at which, according to one meta-analysis, ${ }^{16}$ fracture prevention is consistently seen.

\section{Factors associated with vitamin $D$ deficiency}

Many factors are associated with vitamin D deficiency, some causative (e.g., marked avoidance of ultraviolet radiation, malabsorption), and others being conditions in which vitamin D deficiency or insufficiency is reported frequently (e.g., chronic renal failure) $)^{17,18}$ (mostly level 4 evidence).

Vitamin D deficiency should be considered in patients with osteoporosis, particularly if there is no response to therapy. ${ }^{19}$ Elderly patients living in institutions are at high risk for vitamin D deficiency because of lack of exposure to sunlight. ${ }^{20}$ Absolute avoidance of sunlight increases the risk of vitamin $\mathrm{D}$ deficiency, and vitamin $\mathrm{D}$ supplementation is needed in this situation (level 3 evidence, grade $\mathrm{C}$ recommendation). Sunscreens lower the rate of vitamin D synthesis ${ }^{21}$ but have not been associated with vitamin D deficiency and should not be avoided out of fear of such a deficiency. ${ }^{22,23}$

\section{Summary statements}

1. Measurement of 25-hydroxyvitamin D in the serum (with no restrictions on the timing of collection) is the best indicator of vitamin D sufficiency ${ }^{24}$ (level 2 evidence).

2. In the absence of external laboratory proficiency testing, serum 25-hydroxyvitamin D values from different clinical laboratories cannot be assumed to be comparable ${ }^{7,9,25}$ (level 2 evidence).
3. Monitoring of routine vitamin D supplementation by measurement of serum 25-hydroxyvitamin D is unnecessary (level 4 evidence). Monitoring of high-risk patients and those with osteoporosis should not be performed before three months of standard supplementation (20-50 $\mu \mathrm{g}$ [800-2000 IU daily]) $)^{12}$ (level 2 evidence). Patients taking daily doses above Health Canada's "tolerable upper intake level" (currently set at $50 \mu \mathrm{g}$ [2000 IU]) should undergo monitoring of serum 25-hydroxyvitamin D (level 4 evidence).

\section{Sources of vitamin D}

\section{Exposure to the sun}

Ultraviolet B radiation (wavelength 290-315 nm) promotes synthesis of vitamin D from 7-dehydrocholesterol in the skin. ${ }^{24}$ The amount of exposure needed to achieve adequate vitamin D status depends on latitude, altitude, time of year and day, weather, other aspects of the environment, age, skin pigmentation type, clothing, activity and the amount of skin irradiated. ${ }^{21}$ To obtain $25 \mu \mathrm{g}$ (1000 IU) of vitamin D3 from moderate exposure to ultraviolet $\mathrm{B}$ radiation, a young white person needs exposure at one-quarter of the minimal erythemal dose (4 minutes) to $25 \%$ of the body surface (arms and most of the legs), whereas an older person or a person with darker skin may need as long as 18 minutes $^{26,27}$ (level 2 evidence). Unfortunately, many detrimental effects of ultraviolet $\mathrm{B}$ radiation are cumulative, and one-quarter of the minimal erythemal dose per day would result in a significant amount of ultraviolet B radiation exposure over a summer. For that reason, dermatologists recommend that the safest course is to avoid exposure to the sun and to take vitamin D supplements.

The effects of latitude on vitamin D synthesis may be related to fractures: for each $10^{\circ}$ change in latitude away from the equator, the probability of hip fracture increases by $0.6 \%{ }^{28}$ In wintertime, above $35^{\circ}$ North latitude, sunlight does not contain adequate ultraviolet $\mathrm{B}$ radiation for production of vitamin $\mathrm{D}_{3} .{ }^{29}$ Therefore, Canadians are at risk for seasonal vitamin D insufficiency or deficiency. ${ }^{30-32}$ Although 25hydroxyvitamin D levels in summer may reach or exceed 75 $\mathrm{nmol} / \mathrm{L}$, in winter they can fall by half ${ }^{33}$ (level 3 evidence).

\section{Food sources}

The influence of diet on vitamin D status is minimal (accounting for 3.7-5.9 $\mu \mathrm{g}$ or 148-236 IU daily), and most circulating vitamin D is derived from exposure to sunlight. ${ }^{34}$ The major dietary sources of vitamin D come from Canada's mandatory fortification of margarine, milk (both fluid and powdered forms) and plant-based beverages and from optional fortification of fruit juices and yogurts ${ }^{35}$ (level 2 evidence).

\section{Supplements}

The 2007 Canada Food Guide recommendation that all adults over the age of 50 years take a daily vitamin D supplement of $10 \mu \mathrm{g}(400 \mathrm{IU})^{36}$ should ensure that older Canadians meet the 1997 dietary recommendations from the Institute of Medi- 
cine. ${ }^{2}$ However, this level of intake does not meet the previous recommendation of Osteoporosis Canada of $20 \mu \mathrm{g}$ (800 IU), which was based on data suggesting that this is the minimum dose consistently associated with prevention of fractures $^{1,17}$ (level $1+$ evidence).

When supplements are used to treat vitamin D insufficiency, the amount should be great enough to increase 25hydroxyvitamin D to desirable levels. Daily doses over $50 \mu \mathrm{g}$ (2000 IU) can safely be administered under medical supervision. ${ }^{2}$ Assuming that the patient can absorb an orally administered dose, severe deficiency (rickets or osteomalacia) requires doses as high as $1250 \mu \mathrm{g}$ (50 $000 \mathrm{IU}$ ) daily for two to four weeks, then weekly or biweekly, with monitoring of serum 25-hydroxyvitamin D at one month and three months. Less severe deficiency can be managed with lower doses. ${ }^{5} \mathrm{~A}$ clinically useful estimate is $1 \mathrm{nmol} / \mathrm{L}$ for each microgram of vitamin $\mathrm{D} ; ;^{12,37,38}$ for example, vitamin $\mathrm{D}_{3} 1 \mu \mathrm{g}$ (40 IU) daily raises serum 25 -hydroxyvitamin $\mathrm{D}$ by $0.7-2.0 \mathrm{nmol} / \mathrm{L}$. If diet and a background of moderate sun exposure during summer is assumed to achieve a mean serum 25-hydroxyvitamin D level of $50 \mathrm{nmol} / \mathrm{L}$, then a further $25 \mu \mathrm{g}(1000 \mathrm{IU})$ per day of dietary vitamin $\mathrm{D}_{3}$ may be needed to exceed $75 \mathrm{nmol} / \mathrm{L}$. Some individuals, particularly those deprived of sunlight and those who are elderly, may need greater intake (level 2 evidence).

\section{Safety and toxicity of vitamin D supplementation}

Because of the long half-life of vitamin D accumulation in the tissues, excessive intake of vitamin D has the potential to cause chronic toxic effects, which present as hypercalcemia and renal damage. Most countries have set the "tolerable upper intake level" for vitamin D (the highest daily intake presenting no risk of adverse health effects in almost all individuals in the general population) at $50 \mu \mathrm{g}(2000 \mathrm{IU})$ for adults. ${ }^{2}$ However, this intake level was set without adequate studies of doseresponse relationships or toxicity. Small studies have shown that hypercalcemia or hypercalciuria cannot be elicited in healthy adults who consume up to $250 \mu \mathrm{g}$ (10 $000 \mathrm{IU})$ daily over long periods. ${ }^{12,39}$ Recent reviews have recommended that the tolerable upper intake level be raised to $250 \mu \mathrm{g}$ (10 $000 \mathrm{IU})$ daily, ${ }^{4,39}$ but more studies are needed ${ }^{39}$ If the desirable serum level of 25-hydroxyvitamin $\mathrm{D}$ is at least $75 \mathrm{nmol} / \mathrm{L}$, daily intakes greater than 20-50 $\mu \mathrm{g}$ (800-1000 IU) and as high as $125 \mu \mathrm{g}(5000 \mathrm{IU})$ may be required in some cases ${ }^{40}$ (level 2 and 4 evidence).

There is no convincing evidence of adverse effects of daily intakes up to $125 \mu \mathrm{g}$ (5000 IU). Although the Women's Health Initiative, which used $10 \mu \mathrm{g}$ (400 IU) daily, found an increased incidence of nephrolithiasis, there was no evidence of elevated 25-hydroxyvitamin D in the small number of participants tested, and calciuria was not assessed. ${ }^{41}$

Diseases like sarcoidosis sometimes feature hypercalcemia and/or hypercalciuria, and calcium levels should be monitored in affected patients, particularly in summer. ${ }^{42}$ The vitamin D intake of patients with primary hyperparathyroidism should not be restricted. Vitamin D insufficiency is common in this condition, and repletion may have beneficial effects ${ }^{43,44}$ (level 3 evidence).

There is no evidence that increasing the recommended vitamin D intake for the general population to $20-50 \mu \mathrm{g}$ (800-2000 IU) would cause any medical problems. At this level of vitamin D intake, there is no need to monitor calcium in the serum or urine or to monitor renal function ${ }^{2,40}$ (level 2 evidence, grade B recommendation).

\section{Summary statements}

1. In Canada, some vitamin D is obtained with safe exposure to the sun during the summer months, ${ }^{26,27,45}$ (level 1 evidence), but exposure to sunlight and dietary intake are insufficient to maintain average serum 25-hydroxyvitamin D concentration above $75 \mathrm{nmol} / \mathrm{L}$ throughout the year ${ }^{12,31,32}$ (level 2 evidence).

2. A daily intake of $25 \mu \mathrm{g}$ vitamin $\mathrm{D}_{3}(1000 \mathrm{IU})$ - a safe, commonly available dose - will raise the average serum level of 25 -hydroxyvitamin D by $15-25 \mathrm{nmol} / \mathrm{L}^{12,37}$ (level 2 evidence).

3. The upper level for safe vitamin $D_{3}$ intake has not been well defined but is probably as high as $250 \mu \mathrm{g}$ (10 $000 \mathrm{IU})$ daily $^{12,39}$ (level 2 evidence). In clinical practice, supplementation with this dose of vitamin D is rarely required (level 4 evidence).

\section{Traditional roles of vitamin D}

\section{Effect on bone mineral density}

Vitamin D deficiency is associated with low bone mineral density, a key risk factor for osteoporotic fracture. ${ }^{1}$ Observational studies have shown a positive association between serum 25-hydroxyvitamin D (range $40-90 \mathrm{nmol} / \mathrm{L}$ ) and higher bone density. ${ }^{46-48}$

In older women (> 65 years), daily vitamin $\mathrm{D}_{3} 17.5$ or 20 $\mu \mathrm{g}(700$ or $800 \mathrm{IU})$ resulted in small but significant increases in bone mineral density in the lumbar spine and femoral neck relative to placebo. ${ }^{49,50}$ Similarly, the Women's Health Initiative found, in a subgroup of 2431 women taking vitamin D and calcium supplements, a $1.06 \%$ increase in total hip density $(p<0.001)^{41}$ (level 1 evidence).

\section{Effect on fractures}

Low 25-hydroxyvitamin D concentrations have been associated with fracture. Higher serum 25-hydroxyvitamin D levels were observed in randomized trials that reported a significant reduction in fractures. ${ }^{49,51-53}$ However, the treatment effect varied across these trials, ${ }^{49,51,54-58}$ possibly because of compliance issues $(<80 \%)$ and incomplete assessment of vitamin D status. In their meta-analysis, Bischoff-Ferrari and colleagues ${ }^{16}$ combined data from five trials $(n=9829)$ that used 17.5 or $20 \mu \mathrm{g}$ (700 or $800 \mathrm{IU}$ ) of vitamin $\mathrm{D}_{3}$ and reported a $23 \%$ reduction in nonvertebral fractures. The reduction in risk of fracture was most strongly associated with those doses, provided serum 25-hydroxyvitamin D levels exceeded $75 \mathrm{nmol} / \mathrm{L} .{ }^{16}$

The importance of adequate calcium intake and the primary role of vitamin D in the absorption of dietary calcium were highlighted by a meta-analysis ${ }^{59}$ showing that the combined relative risk (RR) of fracture from 6 trials $(n=45509)$ of vitamin $\mathrm{D}_{3}(10-20 \mu \mathrm{g}$ [400-800 IU]) combined with cal- 
cium was 0.82 (95\% confidence interval [CI] 0.71-0.94). Similarly, a recent cumulative meta-analysis found that calcium intake above $1200 \mathrm{mg}$ daily in combination with $20 \mu \mathrm{g}$ (800 IU) vitamin D provided reduction in fracture risk and prevention of bone loss superior to effects seen with lower calcium intake and $10 \mu \mathrm{g}$ (400 IU) vitamin $\mathrm{D},{ }^{60}$ especially for elderly patients living in institutions, where adherence is assured through supervision of medications. ${ }^{58}$

Vitamin $\mathrm{D}_{3}$ at daily doses of at least $20 \mu \mathrm{g}$ (800 IU) in combination with calcium $(1000 \mathrm{mg})$ reduces the risk of hip and nonvertebral fractures, especially for elderly patients living in institutions ${ }^{16,60}$ Clinical trial evidence for the efficacy of vitamin $\mathrm{D}_{3}$ and calcium in reducing fracture risk in community-dwelling individuals is less strong, ${ }^{57}$ but poor compliance was a major factor in the negative studies. ${ }^{41,52}$ Although $20 \mu \mathrm{g}$ (800 IU) is the lowest dose consistently associated with a bone benefit, it is likely that, for a sizeable minority of individuals, this dose would not be effective. Because higher doses are within the current definition of tolerable upper level, it seems reasonable to recommend 20-50 $\mu \mathrm{g}(800-2000$ IU) for patients at risk for osteoporosis (level 2-4 evidence, grade $\mathrm{B}-\mathrm{D}$ recommendation).

\section{Effect on falls}

Vitamin D may reduce falls through improvements in muscle strength and lower-extremity function. ${ }^{14,61}$ A meta-analysis of five trials that adequately defined and ascertained falls showed that vitamin D significantly reduced the risk (by $22 \%$ ), but this was not the case when the analysis was restricted to the three randomized controlled trials (odds ratio $0.83,95 \%$ CI $0.65-1.06) .^{62}$ The inconsistent effect of vitamin $\mathrm{D}$ in trials may be related to differences in population, dose and method of capturing data on falls. ${ }^{55,61-67}$ There is reasonable evidence that vitamin $\mathrm{D}_{3}$ at a daily dose of $20 \mu \mathrm{g}$ (800 IU) reduces the risk of falls, particularly from trials that adequately ascertained falls ${ }^{62}$ (level 2 evidence).

\section{Summary statements}

1. Supplementation with vitamin $\mathrm{D}_{3}$ and calcium increases bone density in postmenopausal women and in men over age 50 years $^{41,46-50,68,69}$ (level 1 evidence).

2. Vitamin $\mathrm{D}_{3}$ at daily doses of $20 \mu \mathrm{g}$ (800 IU), in combination with calcium $(1000 \mathrm{mg})$, reduces the risk of hip and nonvertebral fractures in elderly people living in institutions $^{16}$ (level 1 evidence). The evidence for communitydwelling individuals is less strong ${ }^{16,70}$ (level 2 evidence).

3. There is evidence that supplementation with $20 \mu \mathrm{g}$ ( 800 IU) vitamin $\mathrm{D}_{3}$ daily reduces the risk of falls, particularly from trials with adequate ascertainment of falls ${ }^{62}$ (level 2 evidence).

\section{Nontraditional roles of vitamin D}

Since the publication of the previous Osteoporosis Canada guidelines in 2002, a wide variety of previously unsuspected biological roles for vitamin D have been explored. Vitamin D (calcitriol) receptors and the enzymes involved in calcitriol synthesis ( $1 \alpha$-hydroxylase, cytochrome P450 27B1 isozyme) and catabolism (24-hydroxylase, cytochrome P450 24 isozyme) are expressed in many tissues, including the skin, colon, prostate, breast, pancreas and heart, as well as the immune system (monocytes, macrophages and lymphocytes). ${ }^{5}$ Calcitriol produced in these tissues is not normally released into the circulation and is not regulated by serum calcium, phosphate or parathyroid hormone. ${ }^{5}$ Calcitriol may lower blood pressure by downregulating renin production, it may stimulate insulin production and secretion by pancreatic $\beta$ cells, and it may modulate immune function through actions on lymphocytes and macrophages. ${ }^{5}$

Significant antiproliferative and prodifferentiation properties have been demonstrated in laboratory studies. ${ }^{71}$ A systematic review of the PubMed database yielded 63 observational studies of vitamin D status in relation to cancer risk, ${ }^{72}$ the majority of which found that lower cancer risk was associated with sufficient vitamin D status. Systematic reviews for colorectal cancer have also found that vitamin D may reduce the risk. $^{73,74}$ In a small randomized trial, daily supplementation with calcium 1400-1500 mg and vitamin $\mathrm{D}_{3} 27.5 \mu \mathrm{g}$ (1100 IU) reduced the risk of all cancers (excluding skin cancer). ${ }^{75}$

In the Women's Health Initiative study, there was no benefit of $10 \mu \mathrm{g}$ (400 IU) with respect to risk of colorectal cancer, but in a nested case-control substudy, low levels of 25hydroxyvitamin D were associated with higher risk of cancer. ${ }^{76}$ Low serum level of 25-hydroxyvitamin D was associated with colon cancer in the Third National Health and Nutrition Examination study ${ }^{34}$ (level 3 evidence).

Vitamin D deficiency, which impairs the synthesis and secretion of insulin in animal models of diabetes mellitus, ${ }^{77}$ has been linked to the risk of diabetes. Epidemiologic studies have suggested a link between vitamin D deficiency in early life and later onset of type 1 diabetes. ${ }^{78}$ One meta-analysis supported an association between vitamin D deficiency and type 2 diabetes. ${ }^{79}$

Although studies of vitamin D in multiple sclerosis have been small, have lacked controls or have included confounding by other variables, high circulating levels of vitamin D have been associated with a lower risk of this condition, and supplementation has been associated with reduced risk. ${ }^{80,81}$

Vitamin D appears to be required in the immune response that leads to killing of intracellular Mycobacterium tuberculosis, which perhaps explains why populations with a high prevalence of vitamin D insufficiency also have susceptibility to microbial infections. ${ }^{82}$ A recent systematic review found fair evidence that vitamin D has a role in modifying the body's response to infection (especially tuberculosis, influenza and viral upper respiratory tract illnesses), but further research is needed. ${ }^{83}$

Despite the appearance of interesting potential benefits of nontraditional actions of vitamin $\mathrm{D}$ in observational studies, no adequately powered or dosed intervention studies have been performed to test these hypotheses. The US Agency for Healthcare Research and Quality has recently released a systematic review of the evidence for vitamin $\mathrm{D}$ affecting health outcomes, which found little or weak evidence supporting the nontraditional actions of vitamin D and could make no recommendations other than that more research is needed. ${ }^{84}$ 


\section{Box 1: Recommendations for vitamin D} supplementation*

1. Adequate vitamin $D$ status, in addition to calcium from diet or supplements, is essential for the prevention of osteoporosis (level 1 evidence, grade A recommendation).

2. Administration of vitamin $D$ and calcium should not be used as the sole treatment for osteoporosis (level 1 evidence, grade A recommendation).

3. The optimal level of serum 25 -hydroxyvitamin $D$ for musculoskeletal benefits is at least $75 \mathrm{nmol} / \mathrm{L}$ (level 2 evidence, grade $\mathrm{B}$ recommendation).

4. Laboratories performing 25-hydroxyvitamin D testing should take part in external proficiency surveys and should demonstrate that values reported for shared samples approximate the consensus of values reported by others (level 4 evidence, grade $D$ recommendation).

5 . In healthy adults at low risk for vitamin D deficiency (i.e., under age 50, without osteoporosis or conditions affecting vitamin $\mathrm{D}$ absorption or action), routine vitamin $\mathrm{D}$ supplementation (10-25 $\mu \mathrm{g}$ [400-1000 IU] daily) is recommended. Serum 25-hydroxyvitamin D should not be measured (level 5 evidence, grade $D$ recommendation).

6. Adults over 50 years of age are at moderate risk for vitamin D deficiency. Supplementation with at least 20-25 $\mu \mathrm{g}(800-1000 \mathrm{IU})$ of vitamin $D_{3}$ daily is recommended. To achieve optimal vitamin D status (> $75 \mathrm{nmol} / \mathrm{L})$, many individuals may require supplementation at greater than $25 \mu \mathrm{g}$ (1000 IU) daily. Doses up to $50 \mu \mathrm{g}$ (2000 IU) are safe and do not require monitoring (level 3 evidence, grade $C$ recommendation).

7. For individuals receiving pharmacologic therapy for osteoporosis, measurement of serum 25-hydroxyvitamin D should follow three to four months of adequate supplementation and should not be repeated if the optimal level is achieved (grade $D$ recommendation).

8. Measurement of serum 25-hydroxyvitamin D is recommended for individuals with recurrent fractures, bone loss despite osteoporosis treatment or comorbid conditions that affect vitamin D absorption or action (grade D recommendation). Dose requirements above Health Canada's current tolerable upper intake level (50 $\mu \mathrm{g}[2000 \mathrm{IU}])$ may be needed, in which case monitoring of serum 25 -hydroxyvitamin $D$ levels is required (level 4 evidence, grade D recommendation).

9. Exposure to natural sunlight, when used in moderation (avoiding sunburn) and individualized to the person's skin type, can contribute to summertime vitamin D sufficiency (level 2 evidence, grade B recommendation).

10. Research is needed to better define the minimum required daily dose and the optimal dose for musculoskeletal and other health benefits and to better establish the tolerable upper level for vitamin D supplementation (grade D recommendation).

*Levels of evidence and grades of recommendation are explained in Table 1.

\section{Summary statements}

1. Vitamin D insufficiency has been associated with malignancies $^{72}$ (especially colorectal cancer ${ }^{73}$ ), diabetes mellitus $^{78}$ multiple sclerosis ${ }^{81}$ and impaired immune response ${ }^{82}$ (level 3 evidence).

2. The benefits of vitamin $\mathrm{D}$ for these nontraditional roles are associated with 25-hydroxyvitamin D levels above 75 $\mathrm{nmol} / \mathrm{L}^{37,72}$ (level 3 evidence).

\section{Approach to supplementation}

There are major deficits in our knowledge of vitamin D, and more research, including well-conducted randomized controlled trials, is needed to define optimal intake levels. Nonetheless, the consensus position of Osteoporosis Canada is that the available evidence of safety and the potential benefits for adults justify recommending that optimal vitamin $\mathrm{D}$ status represents a serum 25-hydroxyvitamin D level of at least $75 \mathrm{nmol} / \mathrm{L}$. In Canada, exposure to sunlight and dietary intake are insufficient to maintain this level, and use of vitamin D supplementation is therefore indicated for most adults. ${ }^{30-32}$

The clinical approach can take into account three "settings," based on suspicion for vitamin D insufficiency and its complications.

People with low risk for vitamin D insufficiency are adults below age 50 years without comorbid conditions affecting vitamin D absorption or action. For these people, supplementation at 10-25 $\mathrm{gg}$ (400-1000 IU) is appropriate, and serum 25-hydroxyvitamin D should not be measured (level 3 evidence, grade D recommendation).

People with moderate risk for vitamin D insufficiency are adults 50 years of age or older, with or without osteoporosis, but without comorbid conditions that affect vitamin D absorption or action. For these people, routine supplementation with vitamin $\mathrm{D}$ is appropriate, and this should be at a dose of 20 $50 \mu \mathrm{g}$ (800-2000 IU) daily (level 2 evidence, grade B recommendation). Serum 25-hydroxyvitamin D should not be measured routinely in initial assessment of these individuals, but if pharmacologic therapy for osteoporosis is prescribed, 25hydroxyvitamin D should be measured after three to four months of an adequate supplementation dose (level 3-5 evidence, grade D recommendation).

People at high risk for adverse outcomes from vitamin D insufficiency include those with recurrent fractures or bone loss despite osteoporosis treatment and/or comorbid conditions that affect vitamin D absorption or action. In these cases, serum 25hydroxyvitamin D should be measured as part of the initial assessment, and supplementation with vitamin D should be based on the measured value. Supplementation dose requirements above the current definition of tolerable upper intake level (50 $\mu \mathrm{g}$ [2000 IU]) may be identified by measuring serum 25-hydroxyvitamin D levels (grade B recommendation).

Vitamin $\mathrm{D}_{3}$ is the preferred supplementary form for humans, with vitamin $\mathrm{D}_{2}$ being available for large-dose preparations. Calcitriol and its analogs are prescription products with narrow margins of safety. They are not synonymous with vitamin $\mathrm{D}$ and are not advised for prevention or routine treatment of osteoporosis. For most adults given a supplement, an initial dose of vitamin $\mathrm{D}_{3}$ of $20-25 \mu \mathrm{g}$ (800-1000 IU) daily, is likely to raise serum 25-hydroxyvitamin D by approximately $15-30 \mathrm{nmol} / \mathrm{L} .^{12,37}$ To achieve desirable vitamin D status (> $75 \mathrm{nmol} / \mathrm{L}$ ) many individuals will require doses greater than this minimum dose.

A weekly dose of $250 \mu \mathrm{g}$ (10 $000 \mathrm{IU})$ vitamin $\mathrm{D}_{3}$ may be more convenient for some patients if available. Some practitioners use vitamin $\mathrm{D}_{2}$ at a dose of $1250 \mu \mathrm{g}$ (50 $\left.000 \mathrm{IU}\right)$ monthly or more frequently as needed. 
Table 3: Key changes to the vitamin D guidelines in the 2002 guidelines for the management of osteoporosis

\begin{tabular}{|c|c|}
\hline 2002 guidelines $^{1}$ & Changes in the current guidelines* \\
\hline $\begin{array}{l}\text { Recommended vitamin D intake from all sources } \dagger \\
\text { - Men and women < } 50 \mathrm{yr}: 400 \mathrm{IU}(10 \mu \mathrm{g}) / \text { day } \\
\text { - Men and women } \geq 50 \mathrm{yr}: 800 \mathrm{IU}(20 \mu \mathrm{g}) / \text { day }\end{array}$ & $\begin{array}{l}\text { For most healthy adults, regardless of age, the recommended vitamin } \\
D_{3} \text { intake is } 800-1000 \mathrm{IU}(20-25 \mu \mathrm{g}) \text { per day. For individuals at high } \\
\text { risk for vitamin } D \text { deficiency, supplementation at doses between } 800 \\
\text { and } 2000 \mathrm{IU}(20-50 \mu \mathrm{g}) \text { per day is recommended, with potential for } \\
\text { higher doses. }\end{array}$ \\
\hline Measurement of serum 25-OH-D not recommended & $\begin{array}{l}\text { For individuals receiving pharmacologic therapy for osteoporosis, } \\
\text { vitamin D deficiency should be considered and serum } 25-O H-D \\
\text { measured, either at initial assessment if the person is already taking } \\
\text { recommended supplementation or after } 3 \text { months of vitamin D } \\
\text { supplementation. }\end{array}$ \\
\hline
\end{tabular}

Note: $25-\mathrm{OH}-\mathrm{D}=25$-hydroxyvitamin D.

*Additional new guidelines are presented in Box 1 .

tThe term "all sources" refers to the total of dietary intake and supplementation.

Our recommendations for the use of vitamin $\mathrm{D}$ are presented in Box 1. Changes from the 2002 guidelines are related most specifically to dose recommendations and are presented in Table 3. A summary of this guideline is also available. ${ }^{85}$

\section{Knowledge gaps}

These guideline recommendations are limited by the fact that most studies in the traditional areas of bone health are flawed by use of low doses and poor adherence. With respect to the effects of vitamin D outside the musculoskeletal system, adequately powered randomized clinical trials of a properly defined effective dose of vitamin D have never been done. The upper margins of dose safety for vitamin D have not been determined by trials using adequate numbers of participants and appropriate durations of dosing, but they are undoubtedly much higher than the current national recommendations.

Despite the inadequacy of clinical trial evidence, we suggest that the low cost of vitamin D supplements, the wide therapeutic window and the favourable risk-benefit ratio justify our recommendations. A daily supplement of $25 \mu \mathrm{g}$ (800 IU) should now be regarded as the minimum dose. Canadians can safely take daily vitamin D supplements up to the current definition of tolerable upper intake level (50 $\mu \mathrm{g}$ [2000 IU]), but doses above that require medical supervision. Research is needed to better define the minimum required daily dose, the optimal dose and the tolerable upper limit of vitamin D for musculoskeletal and other health benefits.

\section{This article has been peer reviewed.}

Competing interests: The authors constituted the Vitamin D Working Group of the Guidelines Committee of the Scientific Advisory Council of Osteoporosis Canada. David A. Hanley has been an investigator in clinical trials, participated in advisory boards or received speaking honoraria from the following companies: Amgen, Merck Frosst Canada, Proctor and Gamble Canada (now Warner Chilcott), sanofi-aventis, Novartis, NPS Pharmaceuticals, Eli Lilly Canada, Pfizer, Wyeth-Ayerst, Roche, Servier, Abbott Laboratories and Nycomed. Glenville Jones serves on the scientific advisory board of the not-for-profit Vitamin D External Quality Assessment
Scheme. He is also on the advisory board and has received a research grant from Cytochroma Inc. and is a member of the Genzyme speakers' bureau. Susan J. Whiting is a member of the International Institute for Nutrition and Bone Health, an educational initiative sponsored by Yoplait. She has received current or recent funding in the form of grants and contracts from the Canadian Institutes of Health Research and the Canadian Foundation for Dietetic Research. She is a nutrition consultant to Osteoporosis Canada. She has presented talks with sponsorship from the Dairy Farmers of Canada, the International Alliance of Dietary/Food Supplement Associations, the Vitamin D Society, GlaxoSmithKline and Amway/Nutrilite. William D. Leslie has received speaker fees and unrestricted research grants from Merck Frosst Canada Ltd; unrestricted research grants from Sanofi-Aventis, Procter and Gamble Pharmaceuticals Canada, Novartis, Amgen Pharmaceuticals Canada and Genzyme Canada; and has served on advisory boards for Genzyme Canada, Novartis and Amgen Pharmaceuticals Canada. Robert G. Josse has received speaking honoraria and/or research grants from and/or sits on advisory boards for the following companies: Eli Lilly Canada, Merck Frosst Canada, Warner Chilcott, Novartis Canada, GlaxoSmithKline, sanofi-aventis and Amgen Canada. None declared for Ann Cranney, David E.C. Cole, Stephanie A. Atkinson, Sidney Feldman, Gregory A. Kline and Cheryl Rosen.

Contributors: All authors are members of the Vitamin D Working Group of the Guidelines Committee of the Scientific Advisory Council of Osteoporosis Canada. All authors participated in the conception and design of the vitamin D guideline project. David Hanley oversaw the writing project, recruited committee members, and edited and revised all section submissions. Ann Cranney wrote the Methods section and the section entitled "Traditional roles of vitamin D" and was one of the reviewers of the abstracts identified in the literature search. Glenville Jones wrote the section entitled "Assessment of vitamin D," Susan Whiting wrote the section entitled "Sources of vitamin D" and William Leslie wrote the section entitled "Nontraditional roles of vitamin D." All authors contributed to the review and revision of the entire manuscript and approved the final version submitted for publication.

Acknowledgements: The document was reviewed and approved by the Guidelines Committee of the Scientific Advisory Council of Osteoporosis Canada (chaired by William D. Leslie): Angela Cheung, Kerry Siminoski, Alexandra Papaioannou, Sophie Jamal, Anthony Hodsman and Jacques Brown. The assistance of Loretta Hillier in editing and abridging this document is greatly appreciated.

Funding: Osteoporosis Canada received a grant from the Ontario Ministry of Health and Long-Term Care to develop these guidelines as a part of a larger project to develop guidelines for the investigation and management of osteoporosis.

Endorsements: Canadian Society of Clinical Chemists, Canadian Association of Nuclear Medicine, Canadian Geriatrics Society, Canadian Orthopaedic Association, Canadian Society of Endocrinology and Metabolism, Dietitians of Canada, Ontario Association of Radiologists, Society of Obstetricians and Gynaecologists of Canada, Canadian Rheumatology Association, Canadian Pharmacists Association and Ontario College of Family Physicians. 


\section{REFERENCES}

1. Brown JP, Josse RG. 2002 clinical practice guidelines for the diagnosis and management of osteoporosis in Canada. CMAJ 2002;167(Suppl):S1-34.

2. Institute of Medicine. Dietary reference intakes for calcium, phosphorus, magne sium, vitamin D and fluoride. Washington (DC): National Academy Press; 1997.

3. Shea BJ, Grimshaw JM, Wells GA, et al. Development of AMSTAR: a measurement tool to assess the methodological quality of systematic reviews. BMC Med Res Methodol 2007;7:10.

4. Jones G. Pharmacokinetics of vitamin D toxicity. Am J Clin Nutr 2008;88:582S-6S.

5. Holick MF. Vitamin D deficiency. N Engl J Med 2007;357:266-81.

6. Armas LA, Hollis BW, Heaney RP. Vitamin $\mathrm{D}_{2}$ is much less effective than vitamin $\mathrm{D}_{3}$ in humans. J Clin Endocrinol Metab 2004;89:5387-91.

7. Binkley N, Krueger D, Cowgill CS, et al. Assay variation confounds the diagnosis of hypovitaminosis D: a call for standardization. J Clin Endocrinol Metab 2004;89: 3152-7.

8. Jones G, Horst R, Carter G, et al. Contemporary diagnosis and treatment of vitamin D-related disorders. J Bone Miner Res 2007;22(Suppl 2):V11-5.

9. Lips P, Chapuy MC, Dawson-Hughes B, et al. An international comparison of serum 25-hydroxyvitamin D measurements. Osteoporos Int 1999;9:394-7.

10. Carter GD, Carter R, Jones J, et al. How accurate are assays for 25-hydroxyvitamin $\mathrm{D}$ ? Data from the international vitamin D external quality assessment scheme. Clin Chem 2004;50:2195-7.

11. Singh RJ. Are clinical laboratories prepared for accurate testing of 25-hydroxy vitamin D? Clin Chem 2008;54:221-3.

12. Heaney RP, Davies KM, Chen TC, et al. Human serum 25-hydroxycholecalciferol response to extended oral dosing with cholecalciferol. Am J Clin Nutr 2003;77:204-10.

13. Bacon CJ, Gamble GD, Horne AM, et al. A comparison of three high dose oral vitamin $\mathrm{D}_{3}$ supplementation regimens. J Bone Miner Res 2007;22(Suppl 1):S126

14. Bischoff-Ferrari HA, Dietrich T, Orav EJ, et al. Higher 25-hydroxyvitamin D concentrations are associated with better lower-extremity function in both active and inactive persons aged $\geq 60$ y. Am J Clin Nutr 2004;80:752-8.

15. Heaney RP. Functional indices of vitamin D status and ramifications of vitamin $D$ deficiency. Am J Clin Nutr 2004;80(Suppl):1706S-1709S.

16. Bischoff-Ferrari HA, Willett WC, Wong JB, et al. Fracture prevention with vitamin D supplementation: a meta-analysis of randomized controlled trials. JAMA 2005;293:2257-64.

17. Gaugris S, Heaney RP, Boonen S, et al. Vitamin D inadequacy among postmenopausal women: a systematic review. QJM 2005;98:667-76.

18. Weatherall M. A meta-analysis of 25 hydroxyvitamin $D$ in older people with fracture of the proximal femur. NZ Med J 2000;113:137-40.

19. Holick MF, Siris ES, Binkley N, et al. Prevalence of vitamin D inadequacy among postmenopausal North American women receiving osteoporosis therapy. J Clin Endocrinol Metab 2005;90:3215-24.

20. Webb AR, Kline L, Holick MF. Influence of season and latitude on the cutaneous synthesis of vitamin $\mathrm{D}_{3}$ : exposure to winter sunlight in Boston and Edmonton will not promote vitamin $\mathrm{D}_{3}$ synthesis in human skin. J Clin Endocrinol Metab 1988;67:373-8

21. Matsuoka LY, Wortsman J, Hollis BW. Use of topical sunscreen for the evaluation of regional synthesis of vitamin $\mathrm{D}_{3}$. J Am Acad Dermatol 1990;22:772-5.

22. Barger-Lux MJ, Heaney RP. Effects of above average summer sun exposure on serum 25-hydroxyvitamin D and calcium absorption. J Clin Endocrinol Metab 2002;87:4952-6.

23. Marks R, Foley PA, Jolley D, et al. The effect of regular sunscreen use on vitamin $\mathrm{D}$ levels in an Australian population. Results of a randomized controlled trial. Arch Dermatol 1995;131:415-21.

24. Hollis BW. Circulating 25-hydroxyvitamin D levels indicative of vitamin D sufficiency: implications for establishing a new effective dietary intake recommendation for vitamin D. J Nutr 2005;135:317-22.

25. Hollis BW. The determination of circulating 25-hydroxyvitamin D: no easy task [editorial]. J Clin Endocrinol Metab 2004;89:3149-51.

26. Working Group of the Australian and New Zealand Bone and Mineral Society, Endocrine Society of Australia, Osteoporosis Australia. Vitamin D and adult bone health in Australia and New Zealand: a position statement. Med J Aust 2005; 182:281-5.

27. Webb AR. Who, what, where and when - influences on cutaneous vitamin D synthesis. Prog Biophys Mol Biol 2006;92:17-25.

28. Johnell O, Borgstrom F, Jonsson B, et al. Latitude, socioeconomic prosperity, mobile phones and hip fracture risk. Osteoporos Int 2007;18:333-7.

29. Holick MF. Sunlight and vitamin D for bone health and prevention of autoimmune diseases, cancers, and cardiovascular disease. Am J Clin Nutr 2004;80(Suppl): 1678S-88S

30. Roth DE, Martz P, Yeo R, et al. Are national vitamin D guidelines sufficient to maintain adequate blood levels in children? Can J Public Health 2005;96:443-9.

31. Rucker D, Allan JA, Fick GH, et al. Vitamin D insufficiency in a population of healthy western Canadians. CMAJ 2002;166:1517-24.

32. Vieth R, Cole DE, Hawker GA, et al. Wintertime vitamin D insufficiency is common in young Canadian women, and their vitamin D intake does not prevent it. Eur J Clin Nutr 2001:55:1091-7.

33. Meier C, Woitge HW, Witte K, et al. Supplementation with oral vitamin $\mathrm{D}_{3}$ and calcium during winter prevents seasonal bone loss: a randomized controlled openlabel prospective trial. J Bone Miner Res 2004;19:1221-30.

34. Freedman DM, Looker AC, Chang SC, et al. Prospective study of serum vitamin D and cancer mortality in the United States. J Natl Cancer Inst 2007;99:1594-602.
35. Canadian nutrient file. Ottawa (ON): Health Canada; 1997. Available: www.hcsc.gc.ca/fn-an/nutrition/fiche-nutri-data/index_e.html (accessed 2007 Sept. 9).

36. Canada Food Guide: vitamin D for people over 50: background. Ottawa (ON): Health Canada; 2007. Available: www.hc-sc.gc.ca/fn-an/food-guide-aliment/context /evid-fond/vita_d_e.html (accessed 2007 Sept. 9).

37. Bischoff-Ferrari HA, Giovannucci E, Willett WC, et al. Estimation of optimal serum concentrations of 25-hydroxyvitamin D for multiple health outcomes. Am J Clin Nutr 2006;84:18-28

38. Cranney A, Horsley T, O'Donnell S, et al. Effectiveness and safety of vitamin D in relation to bone health. Evidence Report/Technology Assessment No. 158 (prepared by University of Ottawa Evidence-based Practice Center [UO-EPC] under contract 290-02-0021). AHRQ Publ. No. 07-E013. Rockville (MD): Agency for Healthcare Research and Quality; 2007.

39. Hathcock JN, Shao A, Vieth R, et al. Risk assessment for vitamin D. Am J Clin Nutr 2007;85:6-18

40. Aloia JF, Patel M, Dimaano R, et al. Vitamin D intake to attain a desired serum 25hydroxyvitamin D concentration. Am J Clin Nutr 2008;87:1952-8.

41. Jackson RD, LaCroix AZ, Gass M, et al. Calcium plus vitamin D supplementation and the risk of fractures. N Engl J Med 2006;354:669-83

42. Bonnema SJ, Moller J, Marving J, et al. Sarcoidosis causes abnormal seasonal variation in 1,25-dihydroxy-cholecalciferol. J Intern Med 1996;239:393-8.

43. Grey A, Lucas J, Horne A, et al. Vitamin D repletion in patients with primary hyperparathyroidism and coexistent vitamin D insufficiency. J Clin Endocrinol Metab 2005;90:2122-6.

44. Kantorovich V, Gacad MA, Seeger LL, et al. Bone mineral density increases with vitamin D repletion in patients with coexistent vitamin D insufficiency and primary hyperparathyroidism. J Clin Endocrinol Metab 2000;85:3541-3.

45. Lucas R, McMichael T, Smith W, et al. Solar ultraviolet radiation: global burden of disease from solar ultraviolet radiation. Geneva (Switzerland): World Health Organization; 2006.

46. Bischoff-Ferrari HA, Dietrich T, Orav EJ, et al. Positive association between 25hydroxy vitamin D levels and bone mineral density: a population-based study of younger and older adults. Am J Med 2004;116:634-9.

47. Dawson-Hughes B, Heaney RP, Holick MF, et al. Estimates of optimal vitamin D status. Osteoporos Int 2005; 16:713-6.

48. Stone K, Bauer DC, Black DM, et al. Hormonal predictors of bone loss in elderly women: a prospective study. The Study of Osteoporotic Fractures Research Group. J Bone Miner Res 1998;13:1167-74.

49. Dawson-Hughes B, Harris SS, Krall EA, et al. Effect of calcium and vitamin D supplementation on bone density in men and women 65 years of age or older. $N$ Engl J Med 1997;337:670-6.

50. Grados F, Brazier M, Kamel S, et al. Effects on bone mineral density of calcium and vitamin D supplementation in elderly women with vitamin D deficiency. Joint Bone Spine 2003;70:203-8.

51. Chapuy MC, Pamphile R, Paris E, et al. Combined calcium and vitamin $\mathrm{D}_{3}$ supplementation in elderly women: confirmation of reversal of secondary hyperparathyroidism and hip fracture risk: the Decalyos II study. Osteoporos Int 2002;13:257-64.

52. Gerdhem P, Ringsberg KA, Obrant KJ, et al. Association between 25-hydroxy vitamin D levels, physical activity, muscle strength and fractures in the prospective populationbased OPRA Study of Elderly Women. Osteoporos Int 2005;16:1425-31.

53. Cauley JA, LaCroix AZ, Wu L, et al. Serum 25-hydroxyvitamin D concentrations and risk for hip fractures. Ann Intern Med 2008;149:242-50.

54. Chapuy MC, Arlot ME, Duboeuf F, et al. Vitamin $\mathrm{D}_{3}$ and calcium to prevent hip fractures in the elderly women. N Engl J Med 1992;327:1637-42.

55. Grant AM, Avenell A, Campbell MK, et al. Oral vitamin $\mathrm{D}_{3}$ and calcium for secondary prevention of low-trauma fractures in elderly people (Randomised Evaluation of Calcium Or vitamin D, RECORD): a randomised placebo-controlled trial. Lancet 2005;365:1621-8.

56. Lips P, Graafmans WC, Ooms ME, et al. Vitamin D supplementation and fracture incidence in elderly persons. A randomized, placebo-controlled clinical trial. Ann Intern Med 1996;124:400-6.

57. Porthouse J, Cockayne S, King C, et al. Randomised controlled trial of calcium and supplementation with cholecalciferol (vitamin $\mathrm{D}_{3}$ ) for prevention of fractures in primary care. BMJ 2005;330:1003.

58. Trivedi DP, Doll R, Khaw KT. Effect of four monthly oral vitamin $\mathrm{D}_{3}$ (cholecalciferol) supplementation on fractures and mortality in men and women living in the community: randomised double blind controlled trial. BMJ 2003;326:469.

59. Boonen S, Lips P, Bouillon R, et al. Need for additional calcium to reduce the risk of hip fracture with vitamin D supplementation: evidence from a comparative meta-analysis of randomized controlled trials. J Clin Endocrinol Metab 2007;92:1415-23.

60. Tang BM, Eslick GD, Nowson C, et al. Use of calcium or calcium in combination with vitamin $\mathrm{D}$ supplementation to prevent fractures and bone loss in people aged 50 years and older: a meta-analysis. Lancet 2007;370:657-66.

61. Bischoff HA, Stahelin HB, Dick W, et al. Effects of vitamin D and calcium supplementation on falls: a randomized controlled trial. J Bone Miner Res 2003;18:343-51.

62. Bischoff-Ferrari HA, Dawson-Hughes B, Willett WC, et al. Effect of vitamin D on falls: a meta-analysis. JAMA 2004;291:1999-2006.

63. Bischoff-Ferrari HA, Orav EJ, Dawson-Hughes B. Effect of cholecalciferol plus calcium on falling in ambulatory older men and women: a 3-year randomized controlled trial. Arch Intern Med 2006;166:424-30.

64. Broe KE, Chen TC, Weinberg J, et al. A higher dose of vitamin D reduces the risk of falls in nursing home residents: a randomized, multiple-dose study. J Am Geriatr Soc 2007;55:234-9. 
65. Flicker L, MacInnis RJ, Stein MS, et al. Should older people in residential care receive vitamin D to prevent falls? Results of a randomized trial. J Am Geriatr Soc 2005;53:1881-8.

66. Dhesi JK, Jackson SH, Bearne LM, et al. Vitamin D supplementation improves neuromuscular function in older people who fall. Age Ageing 2004;33:589-95.

67. Pfeifer M, Begerow B, Minne HW, et al. Effects of a short-term vitamin D and calcium supplementation on body sway and secondary hyperparathyroidism in elderly women. J Bone Miner Res 2000;15:1113-8.

68. Cooper L, Clifton-Bligh PB, Nery ML, et al. Vitamin D supplementation and bone mineral density in early postmenopausal women. Am J Clin Nutr 2003;77:1324-9.

69. Bischoff-Ferrari HA, Kiel DP, Dawson-Hughes B, et al. Dietary calcium and serum 25-hydroxyvitamin D status in relation to BMD among U.S. adults. $J$ Bone Miner Res 2009;24:935-42.

70. Bischoff-Ferrari HA, Willett WC, Wong JB, et al. Prevention of nonvertebral fractures with oral vitamin D and dose dependency: a meta-analysis of randomized controlled trials. Arch Intern Med 2009;169:551-61.

71. Masuda S, Jones G. Promise of vitamin D analogues in the treatment of hyperproliferative conditions. Mol Cancer Ther 2006;5:797-808.

72. Garland CF, Garland FC, Gorham ED, et al. The role of vitamin D in cancer prevention. Am J Public Health 2006;96:252-61.

73. Gorham ED, Garland CF, Garland FC, et al. Vitamin D and prevention of colorectal cancer. J Steroid Biochem Mol Biol 2005;97:179-94.

74. Grant WB, Garland CF. A critical review of studies on vitamin D in relation to colorectal cancer. Nutr Cancer 2004;48:115-23.

75. Lappe JM, Travers-Gustafson D, Davies KM, et al. Vitamin D and calcium supplementation reduces cancer risk: results of a randomized trial. Am J Clin Nutr 2007;85:1586-91.

76. Wactawski-Wende J, Kotchen JM, Anderson GL, et al. Calcium plus vitamin D supplementation and the risk of colorectal cancer. N Engl J Med 2006;354:684-96.

77. Zeitz U, Weber K, Soegiarto DW, et al. Impaired insulin secretory capacity in mice lacking a functional vitamin D receptor. FASEB J 2003;17:509-11.

78. Mathieu C, Gysemans C, Giulietti A, et al. Vitamin D and diabetes. Diabetologia 2005;48:1247-57.

79. Pittas AG, Lau J, Hu FB, et al. The role of vitamin D and calcium in type 2 diabetes. A systematic review and meta-analysis. J Clin Endocrinol Metab 2007;92: 2017-29.

80. Brown SJ. The role of vitamin D in multiple sclerosis. Ann Pharmacother 2006; 40:1158-61.
81. Munger KL, Levin LI, Hollis BW, et al. Serum 25-hydroxyvitamin D levels and risk of multiple sclerosis. JAMA 2006;296:2832-8.

82. Liu PT, Stenger S, Li H, et al. Toll-like receptor triggering of a vitamin D-mediated human antimicrobial response. Science 2006;311:1770-3.

83. Yamshchikov AV, Desai NS, Blumberg HM, et al. Vitamin D for treatment and prevention of infectious diseases: a systematic review of randomized controlled trials. Endocr Pract 2009;15:438-49.

84. Chung M, Balk EM, Brendel M, et al. Vitamin D and calcium: a systematic review of health outcomes. Evidence Report/Technology Assessment No. 183 (prepared by Tufts Evidence-based Practice Center under contract HHSA 290-2007-10055I). AHRQ Publ. No. 09-E015. Rockville (MD): Agency for Healthcare Research and Quality; 2009.

85. Hanley DA, Cranney A, Jones G, et al.; for the Guidelines Committee of the Scientific Advisory Council of Osteoporosis Canada. Vitamin D in adult health and disease: a summary statement from Osteoporosis Canada. CMAJ 2010. DOI: 10.1503/cmaj.091062.

Correspondence to: Dr. David A. Hanley, University of Calgary

Health Sciences Centre, 3330 Hospital Drive NW, Calgary AB

T2N 4N1; dahanley@ucalgary.ca

This full review and guideline of vitamin D in adult health and disease was prepared by a committee of authors chosen by the Guidelines Committee of the Scientific Advisory Council of Osteoporosis Canada. The guideline is an update of the vitamin D section of the complete osteoporosis clinical practice guidelines of Osteoporosis Canada, published in 2002. A summary of this article is available online at www.cmaj.ca. 